\title{
Population demography and spatial ecology of a reintroduced lion population in the Greater Makalali Conservancy, South Africa
}

\author{
D. Druce, Heleen Genis, J. BraAk, Sophie Greatwood, Audrey Delsink, R. Kettles, \\ L. HuNTER and R. SLOTOW
}

Druce, D., Heleen Genis, J. Braak, Sophie Greatwood, Audrey Delsink, R. Kettles, L. Hunter and R. Slotow. 2004. Population demography and spatial ecology of a reintroduced lion population in the Greater Makalali Conservancy, South Africa. Koedoe 47(1): 103-118. Pretoria. ISSN 0075-6458.

Many recently established small game reserves in southern Africa have introduced lion, and have had to actively manage their populations as the lion are in relatively small $\left(<1000 \mathrm{~km}^{2}\right)$, enclosed areas. This study was undertaken on the Greater Makalali Conservancy $\left(140 \mathrm{~km}^{2}\right)$, Limpopo Province, South Africa to describe population demography and lion movement patterns in order to enhance management decisions. A pride of five lion were introduced to Makalali in December 1994 and since then 35 cubs have been born (11.6\% population growth per year over 7.5 years), 31 of which have been translocated to other reserves. To increase genetic diversity, the two male coalition was removed in May 1999 and another two males introduced during July 1999. During the study, the reserve area was increased by approximately $23 \%$. Although the Makalali lion utilised a smaller home range during winter $\left(75.3 \mathrm{~km}^{2}\right)$ than summer $\left(106.8 \mathrm{~km}^{2}\right)$, this difference was not significant. The core ranges also shifted between seasons, with $46 \%$ of the summer core being utilised during winter. When the new males were introduced, they centred their core range near their release boma. The females also shifted their core range to this region after their young male cubs were moved into the boma. After the Makalali area was increased, the lion increased their home range area, while their core range became reduced and more dispersed. There was no significant difference in the distances the lion moved in a 24 hour period between the two seasons, or before and after the two management actions. The Makalali lion also spent more time than expected in low open woodland and grassland habitats and less than expected in low thickets. We conclude that lion populations can successfully exist within small reserves $\left(<100 \mathrm{~km}^{2}\right)$ and that actions to manage the population can be successful if certain criteria are considered.

Key words: core range, home range, reproduction, territory, movement patterns.

D. Druce, Heleen Genis, Sophie Greatwood, Audrey Delsink, L. Hunter and R. Slotow $\triangle$ (slotow@ukzn.ac.za),School of Biological Sciences, University of KwaZulu-Natal, Durban, 4041 Republic of South Africa; J. Braak and R. Kettles, Makalali Private Game Reserve, P.O. Box 809, Hoedspruit, 1380 Republic of South Africa.

\section{Introduction}

During the last few years there has been a rapid increase in the number of small reserves $\left(<1000 \mathrm{~km}^{2}\right)$ in South Africa. Although some of these reserves have been developed to support the hunting industry, many of them have been formed purely as eco-tourism ventures and to enhance biodiversity conservation. As many of these reserves do not contain all species of animals that would have occurred there in the past, some species have been reintroduced. Many of these reserves have introduced lion in order to attract guests and to enhance the wilderness experience (Cotterill 1995; Vartan 2002). However, due to the small size of these reserves, many are only able to sustain small numbers of lion and may even only be able to support one pride. Active management is, therefore, required in these reserves for a number of ecological reasons as well as to enhance tourist sightings. 


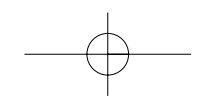

As many of the lion populations are isolated, little or no immigration or emigration occurs, with the result that populations may become inbred (Packer 1996) and need to be manipulated in order to manage genetic diversity (Grubbich 2001). Most managers believe that lion numbers have to be controlled in order reduce their impact on prey populations and the risk of lion breaking out. Managers generally aim to maintain lion populations without the likely population peaks and crashes in both lion and prey species that may occur if they were left to carry on without manipulation. A number of studies have shown that lion predation may negatively affect prey numbers (Hunter 1998; Peel \& Montagu 1999; Harrington et al. 1999). A management tool that can have an effect on the ungulate distribution, and therefore lion predation and distribution, is that of the provision of artificial waterpoints (Smuts 1976; Mills \& Retief 1984; Kalikawa 1990; Stander 1991; Owen-Smith 1996). As a result, by manipulating lion numbers and factors such as water distribution, managers may be able to reduce predation of certain important species. However, in larger reserves, managers also need to consider the effect of rainfall on the distribution of lion. East (1984) has shown that in arid/eutrophic savannas, total large carnivore biomass is positively correlated with rainfall and that in all areas the biomass of each carnivore species is most closely correlated with the biomass of its preferred size class of prey. By ensuring that lion numbers are kept relatively low, the risk of lion breaking out may also be reduced. A high population density facilitates sub-adult emigration from a pride (Hanby \& Bygott 1987), with the result that a high lion density within a small, enclosed reserve may increase the risk of lion, especially sub-adults, breaking out.

Because these lion populations are contained within small reserves, even a minor management decision could have a large impact on the lion and/or the reserve ecology, e.g., through a negative impact on prey populations, which could then possibly result in less prey for other predators. As a result, in order to generate sustainable management strategies and to manage effectively, managers need to understand the ecology of lion in small, enclosed systems and how lion populations may respond to various management strategies. However, there is very little information available on the ecology of lion within these small reserves and to their response to management actions.

Two major management interventions were implemented during the study: (1) the only male coalition in the reserve was removed and a new coalition introduced in its place and (2) the area of the reserve was increased by $23 \%$ through the addition of part of a neighbouring reserve. The aim of this study was to monitor and to determine the effect of these two management interventions on the population demography and movement patterns of the Makalali lion pride.

\section{Study area}

This study was undertaken in the Greater Makalali Conservancy, Limpopo Province, South Africa $\left(29^{\circ} 09^{\prime} \mathrm{S}, 30^{\circ} 42^{\prime} \mathrm{E}\right)$ between February 1998 and December 2001. Makalali is situated on the Lowveld plain at an altitude of between $300 \mathrm{~m}$ and $500 \mathrm{~m}$ above sea-level. The landscape is a combination of undulating terrain and rocky outcrops. Makalali is found within the savanna biome of southern Africa, with Mixed Lowveld Bushveld (Low \& Rebelo 1996; Type 19) and Mopane Bushveld (Low \& Rebelo 1996; Type 10) as the dominant vegetation types. Makalali contains only one river, the Makhutswi River, a perennial tributary of the Olifants River. Within this riverine belt there is a high diversity of tree species. This river splits Makalali and runs from west to east, through Makalali. Artificial waterpoints have been created in Makalali with some of them being supplied with borehole water, especially during the dry winter months.

Makalali is a relatively dry area with an average annual rainfall of $450 \mathrm{~mm}$. Most of the rains fall in the summer months between October and March. Temperatures in the 

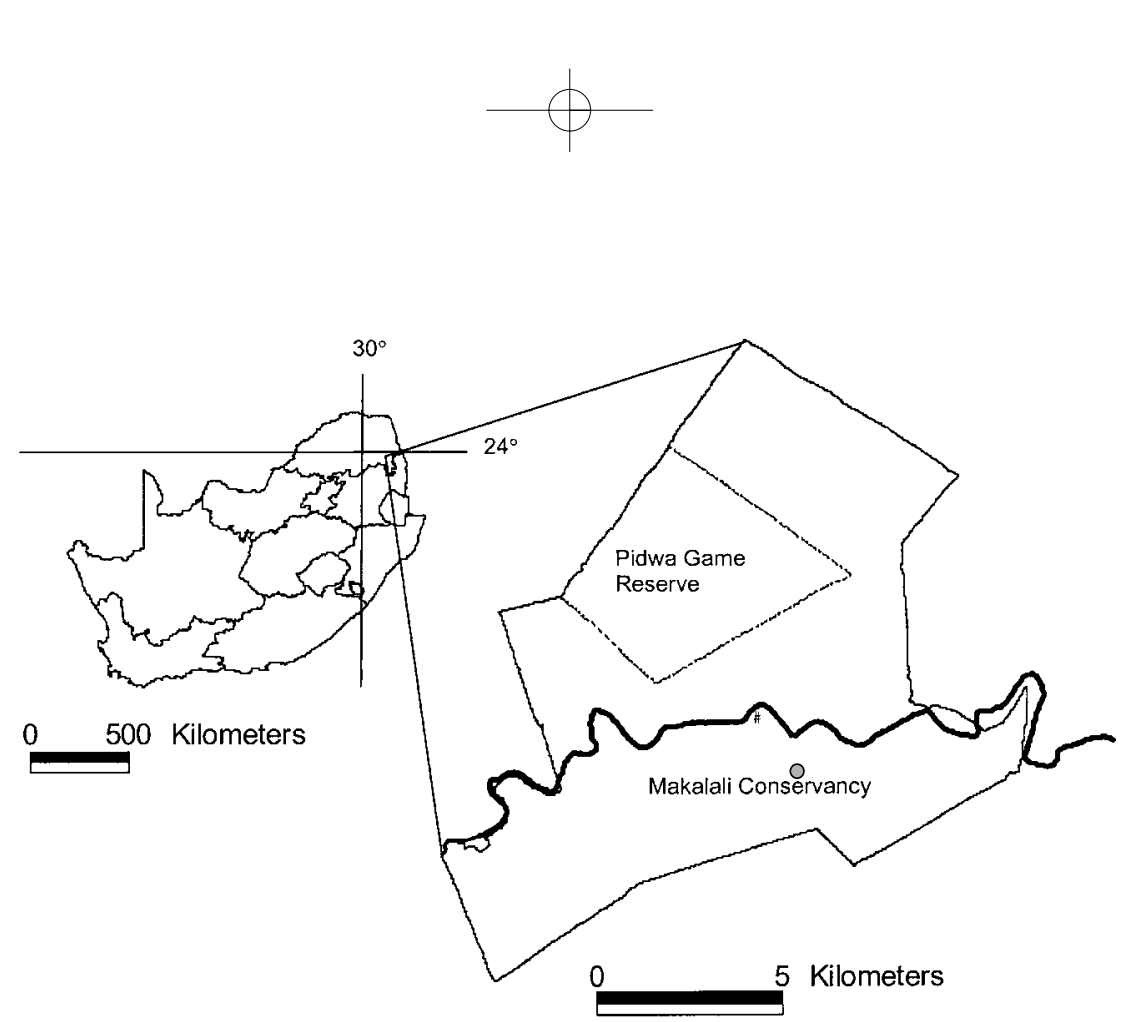

Fig. 1. The Greater Makalali Conservancy with the Pidwa section before the fences were removed (dashed line) in October 2000. The black line through the Conservancy indicates the Makhutswi River and the circle near the centre of the Conservancy indicates the location of the lion release boma.

reserve vary between $3{ }^{\circ} \mathrm{C}$ in winter to above $36{ }^{\circ} \mathrm{C}$ in summer.

Makalali was formed in 1993 by the initial purchase of 7500 ha of cattle ranchland. It has been extended by the acquisition of adjacent farms and the co-operation of surrounding game reserve owners has led to fences being removed between neighboring reserves, with the result that the conservancy is now approximately 14000 ha (Fig. 1). Large mammals that would previously have been in the area were introduced, including a pride of lion introduced during December 1994. This pride, which originated from the Kruger National Park, consisted of five individuals, a mother and her four cubs (two males and two females). The pride settled in well and after only three years the first cubs were born, from a mother-son mating.

\section{Methods}

A lion database has been maintained since the lion were introduced to Makalali in 1994. Individuals were identified by the patterns of dots above their rows of whiskers as well as features such as facial scars and ear tears. The database lists an identity number, name, mother and father, date of birth and death, origin and location (Makalali or where they have been translocated) for each lion. Fathers were assigned to the male coalition that was present in Makalali during that time (there was only one male coalition present at any given time), while the age of the cubs and their association with lionesses, alone or in a group, were used to determine their mother. Data from the date of reintroduction until the end of January 2002 were used to determine patterns in reproduction.

Detailed lion data were recorded on Makalali between 7 February 1998 and 13 December 2001. Most of the information was collected by rangers during game drives, with some of the information being collected by researchers and other staff working on Makalali. As Makalali is an eco-tourism destination with game-viewing offered as a guest activity, rangers track lions on foot if they are not on the roads. Once they have located the lions they return to the vehicle and drive the guests off-road into the sighting. As a result, there were a large number of sightings that did not occur along roads. Lion were generally located between 05:30 and 10:30 in the 
morning and 15:30 and 20:30 in the evening, however, there were periods (such as immediately after the introduction of the new male coalition) that lion movement was monitored outside these hours. Lion data that were recorded included the date, time, individuals present, position (road and GPS), behaviour and when there was a kill, what the prey was. Prey data are presented elsewhere (Druce et al. in press).

\section{Movement patterns}

— Introduction of new pride males

On 21 May 1999, the two Makalali pride males (MAK 1 and MAK 2) were removed from the pride and translocated to Kapama Game Reserve. The same day the two new males (MAK 15 \& MAK 16) were translocated from Kapama and released into the Makalali boma (Fig. 1). This was done in order to introduce new genes into the Makalali pride and to prevent the males from breeding with their offspring.

In order to determine if the introduction of the new males had any effect on the Makalali pride's ranging patterns, we used GPS positions for both the females and the males for the last six months before the removal of the old males and the first six months after the release of the new males to estimate the $50 \%$ kernel ranges and $95 \%$ kernel ranges during these time periods. The Animal Movement Analysis ArcView extension (Hooge \& Eichenlaub 1997) was used in all GIS analyses to estimate the ranges, with the $95 \%$ kernel being used as the estimate of home range and the $50 \%$ kernel as an estimate of core range. A Least Squares Cross-Validation (LSCV) smoothing factor of $500 \mathrm{~m}$ was also used throughout all GIS analyses. Fifty percent was used to denote core area (Mizutani \& Jewell 1998), while $95 \%$ was used to denote home ranges as this excludes occasional sallies outside their normal range (Burt 1943). By including these occasional sallies in the home range, one may generate range estimates that are of a large and bizarre shape (Burt 1943). As a result, most studies define the home range as the smallest area containing $95 \%$ of the distribution (Seaman \& Powell 1996; Apps 1999). Separate maps were produced for the females before and after the introduction of the new males and for the old and new males. We assessed shifts in range by contrasting the old and new core ranges and home ranges.

We determined if males changed the distance that they covered between consecutive days by contrasting distances moved over the last six months the old males were on Makalali with the first six months post-release of the new males. The males and females were considered separately, with the male coalition being considered as one group and the females as individuals. Only the four females that survived the 'take-over' by the new males were used in the analysis as this allowed direct comparison between the two time periods. The Animal Movement Analysis ArcView extension (Hooge \& Eichenlaub 1997) was used to determine the distance between consecutive sightings for the male coalition and each of the females. The number of days between each sighting was determined for the male coalition and the four females and only those sightings that occurred on consecutive days were used in the analysis. When one of the males was not at a sighting (very rarely) the number of days between sightings was taken to be the number of days from the last sighting of that particular male, whether with the other male or alone. The number of days between sightings for each female was recorded as the number of days from the last sighting of that particular female, whether in a group or alone.

The distances moved by the old and new male coalitions during the two six month periods were compared, while the mean distances moved by each individual female were calculated for each six month period, with these means then being compared. As these distances were straight line distances between two points recorded on consecutive days and not recorded by continuous tracking, they cannot be viewed as actual distances moved and should rather be used as an indication of whether change took place or not.

\section{— Removal of Pidwa fence}

During October 2000 the fence between Makalali and Pidwa Game Reserve was removed enlarging the size of the conservancy from 11089 ha to 13600 ha. Fence removal was started at both the northeastern and northwestern sections of the fence simultaneously. The whole fence was systematically removed from the northern boundary on both sides, with the southern section of the fence being removed last. Fence removal was completed within a month.

In order to determine if there was any change in range utilisation before and after reserve expansion, we produced kernel ranges for the males and females for the six-month period before fence removal was started and the first six months after fence removal was begun. GPS positions of all the lion, for these six-month periods were used to produce core and home ranges for the male coalition and the females. The core ranges and home ranges, after fence removal, were compared to those before reserve expansion to determine the percentage overlap. 
With reserve expansion, one may expect the lion to increase the distance that they cover between consecutive days in order to investigate the new area. As a result, we determined the distance that the male coalition and the individual females moved during consecutive days for the six months before and after the removal of the fence was begun. The same methods used in determining the distances moved in consecutive days for the introduction of the new males were employed. The distances moved by the male coalitions between the two time periods were compared, while the mean distances moved by each of the four individual females were calculated for each time period and these means compared.

\section{— Summer and winter patterns}

Various studies have demonstrated that there is an expansion in lion home range during the wet season (Van Orsdol et al. 1985; Hunter 1998) while another reported an expansion during the dry season (Viljoen 1993). Although these changes in home range size could be brought about by purely ecological conditions and changes in herbivore distribution, home range expansion might not be evident in a small reserve especially if lion are using all the area available to them. In order to determine what occurs in Makalali, the year was divided up into two seasons, each of six months. The summer months refer to the beginning of November through to the end of April, while the winter months refer to the beginning of May through to the end of October. This split was chosen as the most rains fall in Makalali between November and April (summer rainfall pattern) and this is also the period that the highest temperatures were recorded. The sighting data were grouped based on these periods and core and home ranges estimated in ArcView. The core and home ranges were compared between winter and summer to determine the percentage overlap between the two time periods.

If lion change their home ranges between seasons, they may also be expected to change the distance that they move between consecutive days. As a result, we calculated the distances that the male coalition and the individual females moved during consecutive days for the summer and winter periods using the same methods used in determining the distances moved between consecutive days during the introduction of the new males. The distances moved by the male coalitions between the two 'seasons' were compared. As all five of the lionesses were present during both summer and winter, the mean distances moved by each of the five individual females were calculated for both 'seasons' and these means compared.

\section{Habitat influences}

Lion select habitats based on factors such as prey availability (East 1984; Creel \& Macdonald 1995; Funston et al. 1998), cover for hunting (Van Orsdol 1984) and protection for cubs (Donkin 2000). In order to determine in what habitat type the Makalali lion spent the greatest proportion of their time, the vegetation map of the Greater Makalali Conservancy was reduced to four habitat types, determined by their degree of openness. The nine vegetation types with their sub-communities and variants, as described by Druce (2000), were reduced to four structural habitat types, the characteristics of which are summarised in Table 1

As no vegetation classification for Pidwa was available, only the sightings recorded before the fence removal were used in the analysis. These sightings were used in the Geoprocessing extension of ArcView to determine the number of sightings per vegetation type and ultimately the number of sightings per structural habitat type. The total number of sightings within each habitat was then compared to the expected number of sightings based on the area each habitat type occupied within the conservancy.

Table 1

Characteristics of the four structural habitat types

\begin{tabular}{llll}
\hline Descriptor & Tree density & Grass and shrub density & Area $\left(\mathrm{km}^{2}\right)$ \\
\hline Low closed woodland & Moderate to dense & Moderate to sparse & 79.06 \\
Low open woodland & Moderate to open & Moderate & 8.1 \\
Low thicket & Dense & Sparse & 18.16 \\
Grasslands & Open & Dense & 5.34 \\
\hline
\end{tabular}


Table 2

Number of cubs born to each female on Makalali until 31/06/02

\begin{tabular}{llcccc}
\hline Number & Name & $\begin{array}{c}\text { Male } \\
\text { cubs }\end{array}$ & $\begin{array}{c}\text { Female } \\
\text { cubs }\end{array}$ & $\begin{array}{c}\text { Total } \\
\text { Birth rate } \\
\text { /female } \\
\text { /month }\end{array}$ \\
\hline MAK 3 & Stickynyawu & 0 & 2 & 2 & 0.07 \\
MAK 4 & One-eye & 8 & 4 & 12 & 0.18 \\
MAK 5 & Bertha & 5 & 2 & 7 & 0.13 \\
MAK 6 & Gertrude & 4 & 3 & 7 & 0.28 \\
MAK 7 & Dorris & 1 & 6 & 7 & 0.29 \\
\hline Total & & 18 & 17 & 35 & \\
\hline
\end{tabular}

${ }^{1}$ Note: Birth rate per female per month was calculated by dividing the number of cubs born to each female by the number of months between their first litter and the end of June 2002 or the date that they left Makalali.

\section{Results}

\section{Population demography until 31/06/02}

Since the introduction of the lion, 35 cubs have been born (Table 2) at a birth rate of $11.6 \%$ per year over 7.5 years. Thirty one of these cubs have been translocated to other reserves (Fig. 2). The only cubs born on the conservancy that have not been translocated are the two female cubs that were born first on the property (MAK $6 \&$ MAK 7) and the two cubs born in January 2002 (MAK 34 \& MAK 35). The only other translocations that have taken place were the exchange of the two males that were introduced first to the reserve. These males were exchanged with two other males from Kapama during 1999. There has only been one lion death on the property. This was the oldest original female who was killed by the new males when they were introduced. She was defending cubs at the time and formed an obstacle to the "takeover' by the new males. One nomadic male (MAK 30) came through the fence into the conservancy towards the end of November 2000 and was last seen on 20 February 2001. It was presumed that he broke out through the fence shortly afterwards, as tracks were seen going out through the fence.
All of the litters ( $n=12$ litters) ranged in size from two to four individuals, with all but two of the litters a single sex litter. After cubs were removed (mean age $=16.6$ months, $n=20$ cubs), there was an average of 6.1 months (approximately 189 days) before their next litter was born $(n=5$ litters). Assuming a gestation period of 110 days (Mills \& Hes 1997), the average interval from cub removal to conception was 79 days (approximately 2.5 months; $n=5$ litters). The average interval between litters when cubs were removed from the conservancy was 22.8 months ( $n=5$ litters) and when the litters were not removed the average inter-birth interval was 15 months $(n=2$ litters). However, only two litters were born while previous litters were still on the conservancy and both litters were born to the same female, indicating that she may have had an inter-birth interval that was shorter than that of the other lionesses. The age at which the Makalali females had their first successful litters ranged from 39 to 51 months with an average of 43.25 months ( $n=4$ females).

\section{Introduction of new pride males}

The two new males from Kapama were kept in the boma from the 21 May 1999 until their release on the morning of 13 July 1999. Immediately they were out of the boma the three smallest male cubs (MAK 12, 13 \& 14), who were 15 months old, were darted, removed from the pride and placed in the boma to ensure that the new males did not kill them as occurs during natural pride takeovers (Packer et al. 1988). They had to be placed in the boma for approximately three months, as the permits for their translocation had not yet been received. For the first 11 days post-release, intense monitoring was carried out, with most of the lions being located every day. On the second day after their release, the new males met the pride for the first time. Initial contact was violent, resulting in the pride of nine scattering in different directions. Seven days after the initial contact (21 July 1999), the males located female MAK 3 and killed her. The following 


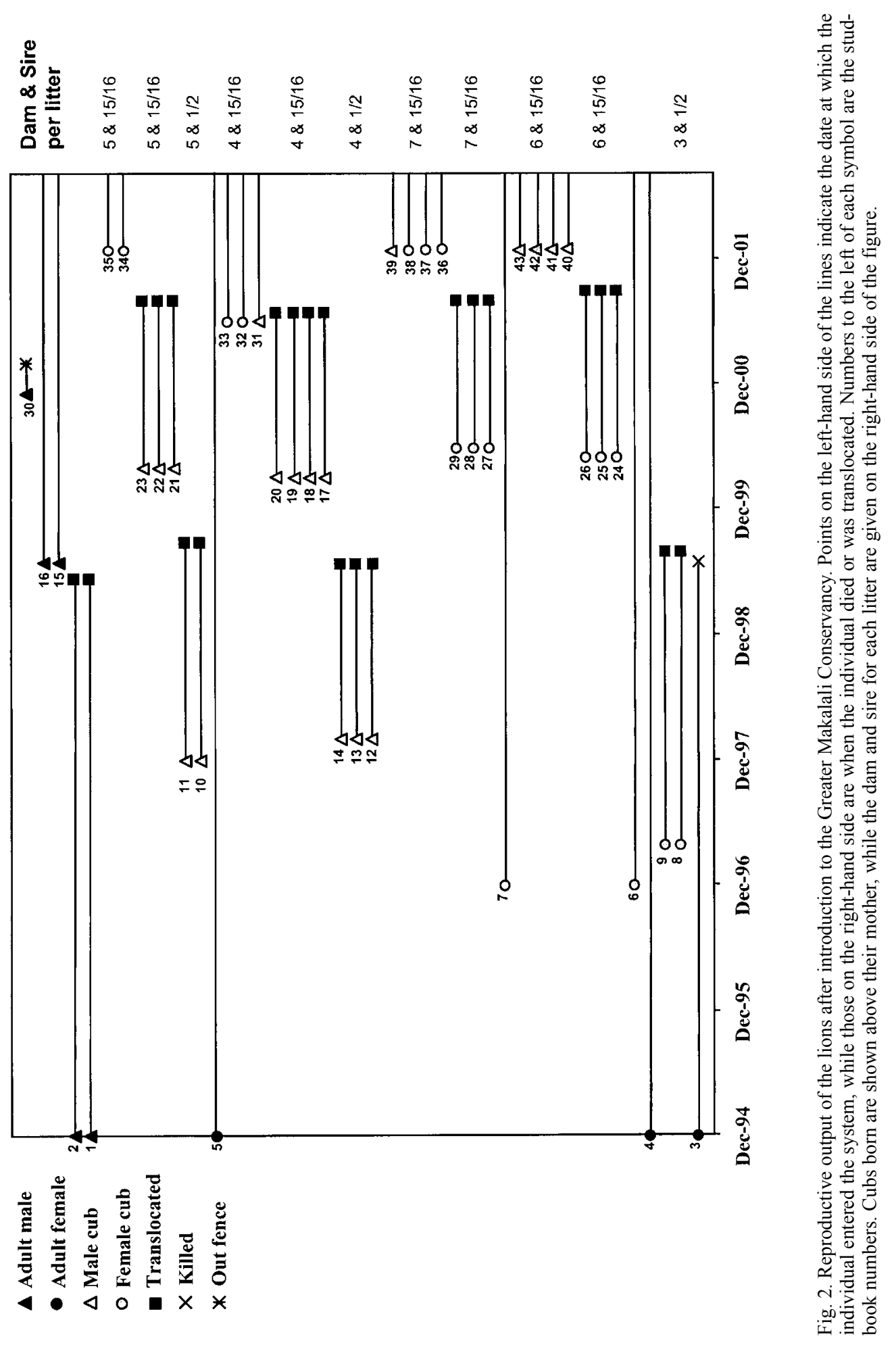




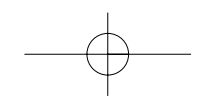

day (22 July 1999) the males located the other females for only the second time postrelease. Initially the females were not worried but soon ran off, without any aggression from the males. Seventeen days after the males were released from the boma they were seen again with the females, with MAK 15 mating with MAK 5 and MAK 16 mating with MAK 6.

For the six-month period before the new pride males were introduced into the conservancy, the females concentrated their core range ( $50 \%$ kernel) in the north western section of the conservancy (Fig. 3a). However, they utilised most of the conservancy with the exception of the far north eastern and far south eastern sections near the boundary fence. Directly after the new males had been introduced, the females' core range shifted further east into the central areas of the conservancy and along the river (Fig. 3b). Twenty three percent of the old core range was included in the new range. After the introduction of the new males, the females did not use the north eastern section of Makalali at all, while $45 \%$ of their old home range (95\% kernel) was included within the new range. The core range (50\% kernel) of the old males (Fig. 3c) was similar to that of the females over the same time period. However, they spent a greater proportion of their time towards the centre of Makalali and their home range (95\% kernel) was not as extensive as that of the females. The new males concentrated their home range along the river for the first six months after release (Fig. 3d). Their core range was near the boma where they had been held prior to release, as well as towards the eastern boundary fence. During this time, the new males' core range only overlapped that of the old males by $12.5 \%$, while their home range overlapped that of the old males by approximately $37 \%$.

ANOVAs were used to compare the distances moved by the male lion. Although the males covered greater distances than the original males on a few occasions (Fig. 4a), there was no significant difference in distance moved in consecutive days between the two male coalitions $\left(\mathrm{F}_{1,42}=0.003\right.$, $p=0.959)$. The female distance data were analysed using a Wilcoxon Paired Signed Ranks test to compare the mean distance for each of the females before and after introduction of the new males. As with the males, there was no significant difference in the distance moved between consecutive days before and after introduction of the new males $(Z=0.000, p=1.0)$. As a result, although the females shifted their home range post-release of the new males, they did not change the distances they were moving between consecutive days.

The first six months after the removal of the old males and the introduction of the new males saw a concentration of the home range for both the new males and the females around the boma from where the males were released. At the same time as the new Makalali males were released, the remaining cubs ( \pm 15 months old) that had not yet been translocated, were removed from the pride and put in the boma to ensure that they were not killed by the new males during a pride take-over. They remained in the boma for the first four months post-release of the new males, while the conservancy manager awaited permits to translocate them. As a result, the new males spent a large portion of their time near the boma trying to get at the young males possibly either because they were males or because they were still cubs.

\section{Removal of Pidwa fence}

For the six months prior to the Pidwa fence removal, the lion core range (50\% kernel) was situated in the centre of Makalali, while their home range (95\% kernel) was concentrated in the central and northwestern areas (Fig. 3e) with only a few sightings in the far northeastern section. After the fence was removed, the lion did not take long to move into the Pidwa section, with the females making use of the new area within the first week after the fences were removed. However, after fence removal the core range became dispersed into much smaller pockets in the centre of Makalali and towards the 
(a) Females before introduction of new males

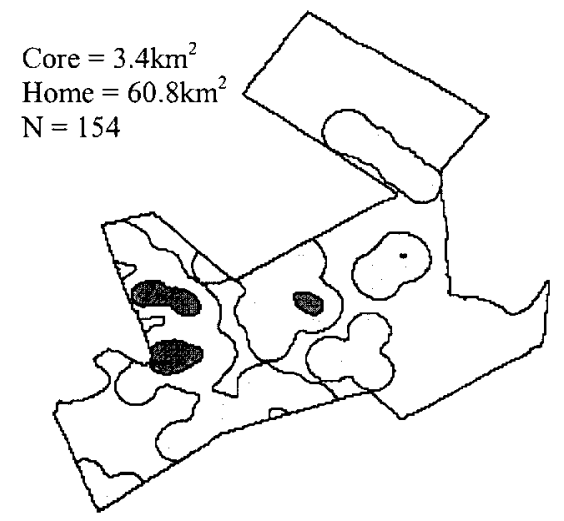

(c) Old males

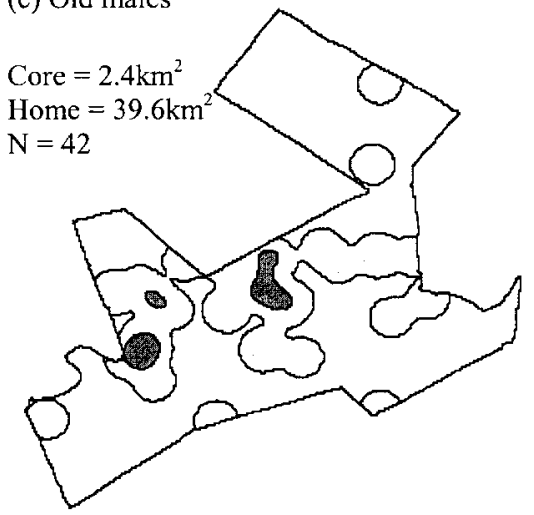

(e) Before fence removal

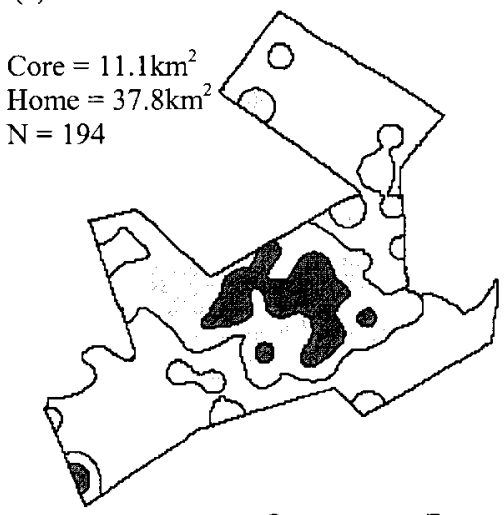

(b) Females after introduction of new males

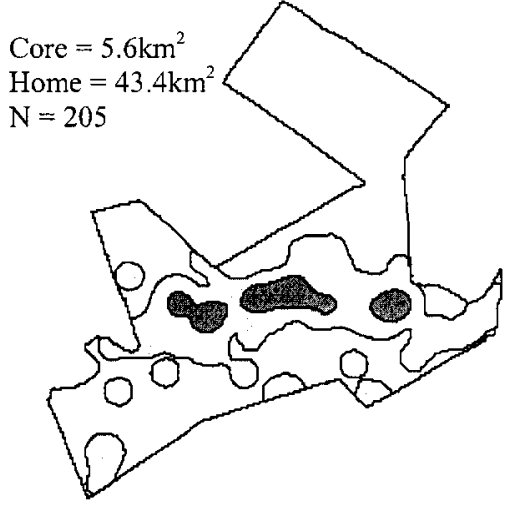

(d) New males

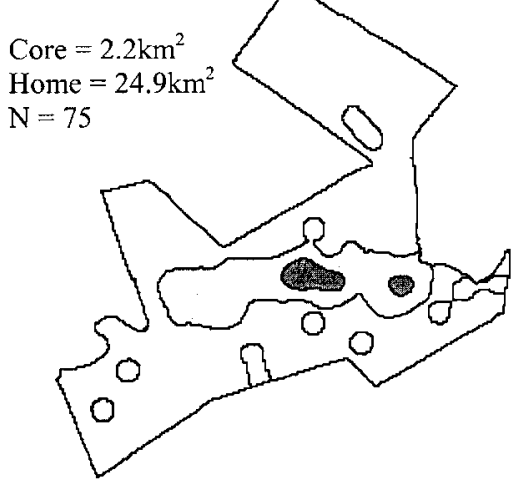

(f) After fence removal

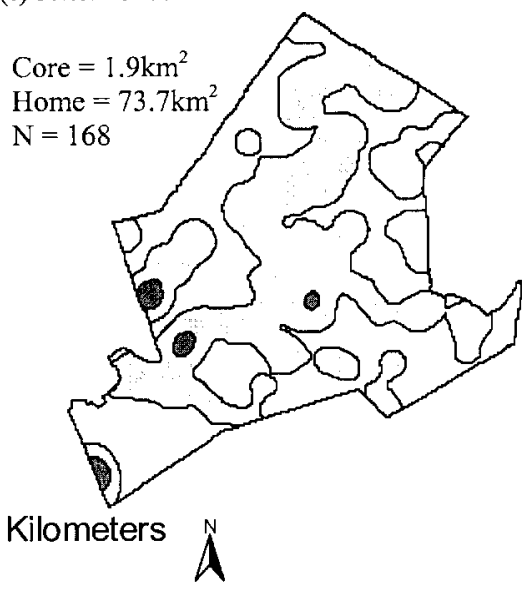

Fig. 3. The effect of two management interventions on the ranging behaviour of the Makalali lions between consecutive days. Core ranges (dark grey shading) are the $50 \%$ kernel ranges while the home ranges (light grey shading) are the $95 \%$ kernel ranges. (a) Female ranges before the introduction of the new males; (b) Female ranges after the introduction of the new males; (c) Old male ranges; d) New male ranges; (e) All lion ranges (males and females combined) before fence removal; (f) All lion ranges (males and females combined) after fence removal. 


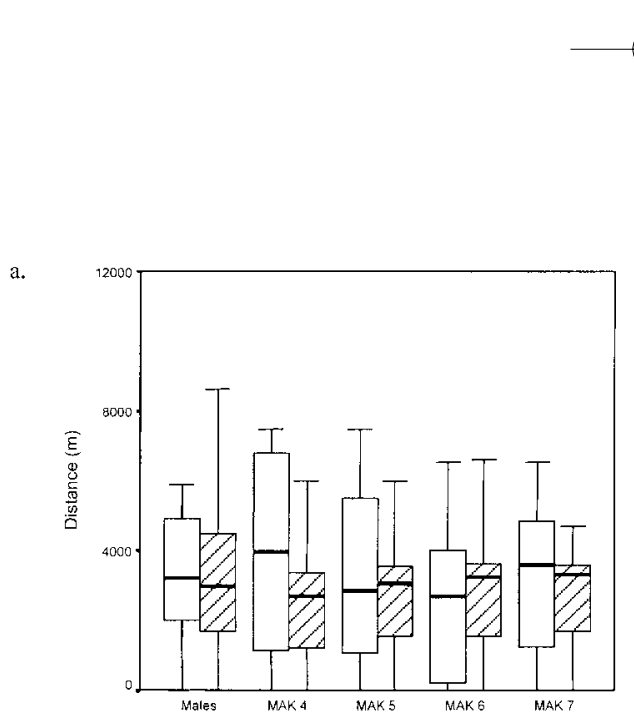

b.
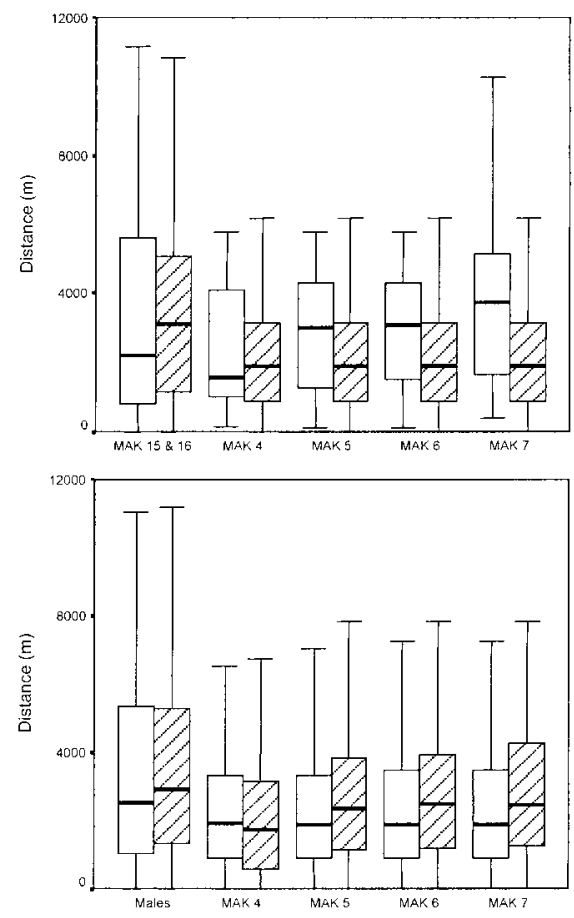

Fig. 4. The effect of management action on daily movement of the Makalali lions. (a) The effect of the introduction of new males to the Makalali Conservancy on the distance moved by the original lions in consecutive days. Distances moved over the first six months post-release of the new males are indicated by hatched boxes, while the distances moved over the last six months the original lions were on the property are indicated by the clear boxes. (b) Effect of reserve area expansion on the distances moved by lions in consecutive days. The six month period immediately before reserve expansion is shown by the clear boxes, while the first six months after fence removal was started are given by the hatched boxes. (c) The effect of season on distances moved by the Makalali lions in consecutive days. Summer is shown by the clear boxes, while winter is shown by hatched boxes. north western and western boundaries (Fig. $3 \mathrm{f})$. This, as well as an increase and dispersal in the home range, indicates that the lion did not spend much time in any areas in particular, but were constantly shifting position and utilising different areas. The core range after the fence removal overlapped the old core range by $5 \%$, while the new home range overlapped the old by 84 $\%$. An interesting point to note is that after the fence was removed the lion tended to use much more of the north eastern and south eastern section than prior to reserve expansion.

Although the core range for the Makalali lion became much more dispersed after Makalali's area was increased, both the ANOVA for the males $\left(\mathrm{F}_{1,222}=0.054\right.$, $p=0.816)$ and the Wilcoxon Paired Signed Ranks Test for the females $(Z=-1.826$, $p=0.068$ ) indicate that there was no significant difference between the distances they moved before and after the fence was removed (Fig. 4b).

The core ranges and home ranges for the Makalali lion for the various management actions and for the summer and winter seasons are relatively small. The core ranges vary from $1.9 \mathrm{~km}^{2}$ (first six months after fence removal) to $11.1 \mathrm{~km}^{2}$ (first six months before fence removal), less than $10 \%$ of the area available to them. This indicates that the Makalali lion do not need an extensive area in which to meet most of their requirements. The home ranges $\left(24.9 \mathrm{~km}^{2}\right.$ to $\left.106.8 \mathrm{~km}^{2}\right)$ also do not extend to the entire reserve area $\left(140 \mathrm{~km}^{2}\right)$.

\section{Summer and winter patterns}

During the summer months, the Makalali lion utilise a large proportion of the reserve (Fig. 5a), with their core range (50\% kernel) concentrated in the central to western areas of Makalali. However, during winter (Fig. 5b) their home range (95\% kernel) is much reduced, with little of the northern, south western and south eastern areas of Makalali being used. Their core range also becomes slightly more concentrated and is 
(a) Summer

$$
\begin{aligned}
& \text { Core }=7.4 \mathrm{~km}^{2} \\
& \text { Home }=106.8 \mathrm{~km}^{2} \\
& \mathrm{~N}=638
\end{aligned}
$$

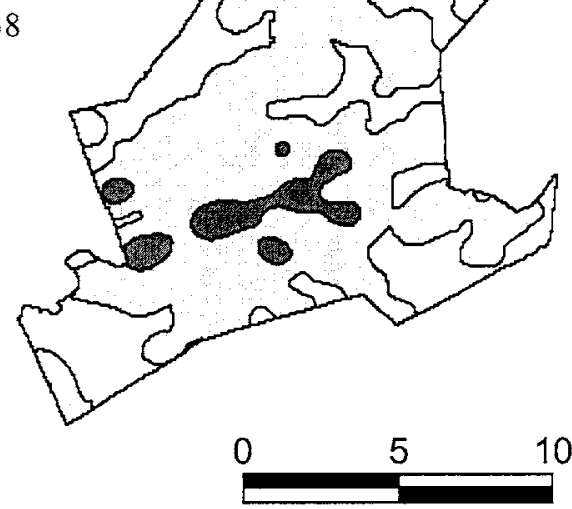

(b) Winter

Core $=5.5 \mathrm{~km}^{2}$

Home $=75.3 \mathrm{~km}^{2}$

$\mathrm{N}=835$

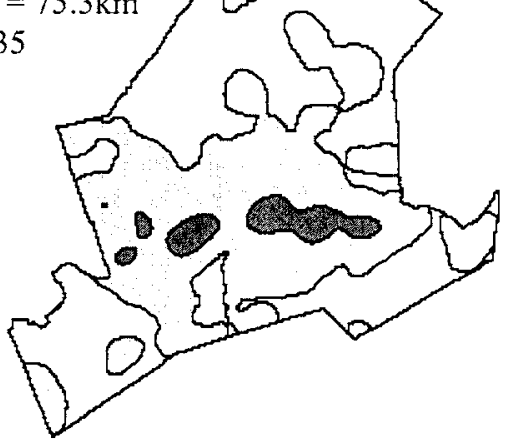

Fig. 5. The effect of season on lion spatial use. Core ranges (50\% kernel ranges) are shown in dark grey, while home ranges ( $95 \%$ kernel ranges) are shown in light grey. (a) All lion ranges during the summer months; (b) All lion ranges during the winter months.

found in the central area along the river, as this is the only permanent water supply towards the end of winter. Forty six percent of the summer core range is utilised during winter, while $59 \%$ of the summer home range is used during winter. Although the kernel ranges increased during the summer months, there was no significant increase in the distance that the males (ANOVA; $\mathrm{F}_{1,167}=0.83, p=0.701$ ) or females (Wilcoxon Paired Signed Ranks Test; $\mathrm{Z}=-1.461$, $p=0.144$ ) moved in consecutive days between the two seasons (Fig. 4c).

\section{Habitat influences}

The low closed woodland constituted the greatest area in the conservancy with the Grassland habitat being the smallest (Table 1).

As lion were tracked on foot if they were not found on the roads, one would not expect a significant difference between the numbers of sightings in each habitat type and the expected based on the area of each habitat type. However, there was a significant difference $\left(\chi^{2}{ }_{0.05,3}=172.53, p<0.05\right)$, with the lion spending more time than expected in the low open woodland and grassland habitats and less than expected in the low thickets (Fig. 6).

\section{Discussion}

In Makalali, the age at first conception, interval between litters, and interval between loss of previous litter and birth of next (in Makalali loss was due to sub-adult cub removal) was within the range reported from both the Serengeti National Park, Tanzania (Schaller 1972; Packer et al. 1988) and Nairobi National Park, Kenya (Rudnai 1973), but was less than half the interval (40 months) of litters within two prides in the Kruger National Park (Funston et al. 2003). The Makalali litter sizes showed a similar trend to those of large reserves in East Africa such as Nairobi National Park (Rudnai 1973), Serengeti National Park (Bertram 1975; Packer \& Pusey 1995) and the 


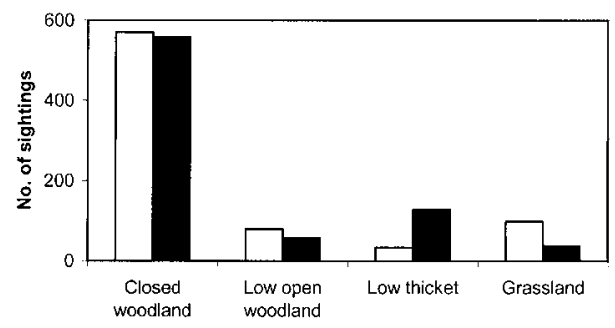

Fig. 6. Habitat selection by lion in Makalali. The actual number of sightings (clear bars) and expected (black bars) number of sightings in the four habitat types investigated.

Ngorongoro Crater (Packer \& Pusey 1995). However, although the sex ratios of individual litters on Makalali were not 1:1 males to females as reported from Nairobi National Park (Rudnai 1973) or between 1:5 to 1:7 (Kruger National Park; Smuts 1976), the sex ratio of all the Makalali litters combined was very close to $1: 1$. This is very similar to the mean ratio of $1: 1.1$ males to females that Funston et al. (2003) reported from all litters within their study area in the Kruger National Park and suggests that although lion in smaller reserves may not face competition from other prides, as occurs in these larger reserves, reproductive patterns and frequency may still be similar as a result of constant management intervention (i.e., removal of cubs).

When introducing lion into a reserve, managers need to consider pride structure. An unnatural situation, as occurred in the Greater Makalali Conservancy, where mother son matings occurred needs to be avoided and females need to be free to mate with unrelated males in order to ensure that no inbreeding occurs.

It was noted that the Makalali lion home range did not completely fill the reserve, which suggests that the lion were satisfying their needs within the reserve and as far as area is concerned, Makalali could possibly support a greater lion population. This was further emphasised by the relatively small core range used by the Makalali lion. This suggests that small conservation areas are able to successfully support lion. However, lion and prey populations within these small areas will need to be constantly monitored and possibly managed to ensure that lion do not have a negative impact on prey populations.

The Makalali lion had a smaller kernel range during the winter months than in the summer, concentrating their activity around the Makhutswi River. Although this reduction in home range in Makalali was small, home range reduction during winter has been shown in other reserves containing a greater number of prides (Van Orsdol et al. 1985; Hunter 1998), while in others, expansion in home range occurs during the dry seasons (Viljoen 1993). In the Savuti area in northern Botswana, ranges increased during winter probably as a result of prey biomass decreasing within the lion ranges forcing them to expand their range in search of prey species (Viljoen 1993). However, in Phinda Game Reserve, South Africa, reduced winter ranges were concentrated around artificially supplied waterpoints (Hunter 1998). In the Makalali Conservancy, most of the waterpoints throughout the conservancy dry up during the winter period, with the Makhutswi River being the only permanent water supply throughout the dry season. As a result, most of the prey species concentrate along the length of the river, resulting in the lion reducing their winter range and concentrating their activity along the river. The provision of artificially supplied water during the dry period in reserves may affect the movement patterns of ungulates (Western 1975; Mills \& Retief 1984; Owen-Smith 1996) and as a result the distribution and ranging patterns of predators such as lion. A study in the Kruger National Park also showed that the number of lion prides in an area increased with an increase of permanent water (Smuts 1976). Therefore, managers of small, enclosed reserves may need to consider the supply of artificial waterpoints within the home ranges of lion in order to ensure there is enough opportunity for prey 
species to escape predation (Hunter 1998) by providing a number of alternative water sources during the dry months.

As with the Makalali lion, the distance travelled by both the Serengeti and Ngorongoro Crater lion was not significantly different between wet and dry seasons (Hanby et al. 1995), however, the Makalali lion did not travel as far, on average, within consecutive days as the east African lion. There was also no difference in distance moved when the conservancy area was increased or when the new males were introduced. The increase in Makalali area also resulted in a shift of the core range (50\% kernel) indicating that an increase in reserve area could result in lion spending less time in certain areas, but rather spreading their activity in order to make use of the new area available to them. This is important with respect to tourist sightings, because if lion spend less time in certain areas, it might become more difficult to locate them. It is interesting to note, however, that although they may increase their range, the distances that they covered in consecutive days did not change. This indicates that although a larger area may be made available to them, males may not increase the distances moved during territory patrols. Hanby et al. (1995) suggested that the lack of water and cover in the Serengeti ecosystem resulted in the Serengeti lion covering greater distances than the Ngorongoro Crater prides in search of those factors. It would appear, therefore, that the availability of cover, water and prey within a system would allow the lions to cover less distance within a 24-hour period.

The lionesses concentrated their activity in the boma area after the release of the males possibly because the cubs had been put in the boma. It has been noted in Makalali on a number of other occasions when cubs have been removed from the pride and put into the boma whilst awaiting translocation, the pride females also moved into the area near the boma. In order to ensure that the lionesses do not shift their movement patterns in response to the capture of their cubs (i.e. ensuring a minimum amount of manipulation), cubs should be translocated immediately after capture and not retained in a boma. A further factor that may have influenced the position of the core area for the first six months postrelease is that this area near the boma is usually used as the core area during winter and the males were released just before the middle of the winter period.

In Phinda, Hunter (1998) noted that lion and cheetah remained near their release site for at least one week post-release and thereafter utilised the area near their release site as part of their home range. Lion released from a boma in Zimbabwe were also reported to have remained within $5 \mathrm{~km}$ of the boma for the first 16 days post-release (Hoare \& Williamson 2001). As a result, the concentration of male lion activity around the boma area after their release is in accordance with other studies, but their continued use of the boma area could have been caused by the fact that the females concentrated their activity over this period in the boma area as well or because of the presence of the young male cubs in the boma. Translocating the cubs immediately may have resulted in the males moving out of the area sooner than they did. However, if managers wanted to shift lion activity to a particular area within a reserve, they could leave cubs awaiting translocation, in a boma within that particular area. This may not be a desirable management technique, however, as it involves a large amount of manipulation and could, therefore, be seen as unethical. A further reason why the male lion could have been concentrating their activity around the boma was because the lionesses concentrated their activity in this area and many would have been ready to mate. This was further supported in that many of the male lion sightings within the first six months post-release where there were females present, only a single lioness was present, with mating often being witnessed.

Seventeen days after the new male lion were released from the boma, they were observed mating with one of the females. These results are similar to those reported from Zimbabwe by Hoare \& Williamson (2001), where on 
day 16 to 20 post-release of a female with sub-adult cubs, she was observed mating with resident males.

The Makalali lion appeared to show a preference for the grassland and low open woodland habitat types and spent less time than expected in low thickets. This trend has also been shown in Phinda Game Reserve, South Africa, where Hunter (1998) demonstrated that lion showed a greater than expected utilisation of the grassland habitat type and less than expected use of dense vegetation types. However, in the Kruger National Park, South Africa, lion select for open tree savannas (similar in structure to the low open woodland in Makalali) and thickets (Donkin 2000). Although areas of denser vegetation may provide better cover for cubs (during most of the study period, there were cubs and sub-adults on the conservancy), food supply has been shown to affect cub survival (Bertram 1975). Open woodlands provide protected areas for cubs, while at the same time provide a good environment for hunting, while grasslands provide much fewer hiding places but better visibility for hunting (Donkin, 2000). Grasslands will also, however, provide greater visibility for prey species when trying to avoid predation, although this advantage may be reduced during the night. This may provide answers as to why the Makalali lion preferred these habitat types.

This study has highlighted the importance of collecting detailed information on lion movements and activities in order to gain a better understanding of lion ecology on a small, enclosed reserve. We conclude that it is possible to exchange male lion coalitions in order to introduce fresh genes into a population without breakouts from the reserve. However, careful note needs to be made of the reproductive state of all the lion on the reserve in order to prevent any mortality through infanticide. Although infanticide occurs naturally in large systems, private game reserves often aim to generate income through the sale of excess animals and as a result, do not want to loose potential income through the death of cubs. Increasing a reserve's area can result in lion successfully utilising the new area, however, this may also result in dispersion of the lion ranges, making it more difficult to locate them. However, managers would need to weigh up benefits gained from increasing a conservation area and allowing an ecological system to operate with less human intervention, with the possible costs of not having as regular lion sightings. Our results also indicate that small reserves can adequately house lion, with core ranges being as small as $1.9 \mathrm{~km}^{2}$ for a six month period (core range after fence removal) and home ranges as small as $24.9 \mathrm{~km}^{2}$ (home range of first six months of new males). Therefore, depending on prey density, lion could be adequately housed on reserves smaller than $100 \mathrm{~km}^{2}$.

\section{Acknowledgements}

The rangers and trackers of Makalali Private Game Reserve and Garonga Safari Camp are thanked for providing data over the years. Martin Bornman and the various students of Africa Conservation Experience are also thanked for providing additional data. Roelof Nieman is thanked for providing information relating to management carried out within the Greater Makalali Conservancy. Yvonne Ebertson and Paul Woods are thanked for their generous financial support and interest in the project, through their donations to the Makalali Land \& Wildlife Trust. Craig Packer is thanked for providing funding from the University of Minnesota and MGM Grand. Financial support was also provided by the Makalali Land \& Wildlife Trust, a THRIP Grant (no. 1897) and a NRF Grant (2053623), while L.H. was a NRF post-Doctoral fellow.

\section{References}

APPS, C.D. 1999. Space-use, diet, demographics and topographic associations of Lynx in the Canadian Rocky Mountains: A study. USDA Forest Service Research Papers 1-11.

BERTRAM, B.C.R. 1975. Social factors influencing reproduction in wild lions. Journal of Zoology, London 177: 463-482.

BURT, W.H. 1943. Territoriality and home range concepts as applied to mammals. Journal of Mammalogy 24: 346-352. 


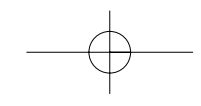

CotteriLl, A.H. 1995. Lions (Panthera leo) on a commercial wildlife ranch: A Zimbabwean casestudy and feasibility assessment. MSc thesis, University of Zimbabwe.

Creel, S. \& D. Macdonald. 1995. Sociality, group size and reproductive suppression among carnivores. Advances in the Study of Behavior 24: 203-257.

Donkin, D.A. 2000. Lion spatial ecology: The effect of habitat on lion group dynamics. MSc thesis, University of Natal, Durban.

DrucE, D.J. 2000. Factors affecting millipede, centipede and scorpion diversity in a savanna environment. MSc thesis, University of Natal, Durban.

Druce, D.J., H. Genis, J. Braak, S. Greatwood, A. Delsink, R. Kettles, L. Hunter \& R. Slotow. In press. Prey selection of a reintroduced lion popultion in the Greater Makalali Conservancy, South Africa. African Zoology.

EAST, R. 1984. Rainfall, soil nutrient status and biomass of large African savanna mammals. African Journal of Ecology 22: 245-270.

Funston, P.J., M.G.L. Mills, H.C. Biggs \& P.K.R. RICHARDSON. 1998. Hunting by male lions: ecological influences and socioecological implications. Animal Behaviour 56: 1333-1345.

Funston, P.J., M.G.L. Mills, P.K.R. RichaRdson \& A.S. VAN JAARSVELD. 2003. Reduced dispersal and opportunistic territory acquisition in male lions. Journal of Zoology, London 259: 131-142.

GRUBBiCH, J.D. 2001. Genetic variation within and among fragmented populations of South African lions Panthera leo: implications for management. MSc thesis, University of Pretoria.

HanBY, J.P. \& J.D. BYGOTT. 1987. Emigration of subadult lions. Animal Behavior 35: 161-169.

Hanby, J.P., J.D. Bygott \& C. Packer. 1995. Ecology, demography and behaviour of lions in two contrasting habitats: Ngorongoro Crater and the Serengeti Plains. Pp. 315-331. In: SinclaIR, A.R.E. \& P. ARCESE (eds.). Serengeti II. Chicago: Chicago Press.

Harrington, R., N. Owen-Smith, P.C. Viljoen, H.C. Biggs, D.R. MAson \& P. Funston. 1999. Establishing the causes of the roan antelope decline in the Kruger National Park, South Africa. Biological Conservation 90: 69-78.

Hoare, R.E. \& J. Williamson. 2001. Assisted reestablishment of a resident pride of lions from a largely itinerant population. South African Journal of Wildlife Research 31: 179-182.

Hooge, P.N. \& B. Eichenlaub. 1997. Animal movement extension to ArcView version 1.1. Alaska Biological Science Center. Anchorage: U.S. Geological Survey.
HunTER, L.T.B. 1998. The behavioural ecology of reintroduced lions and cheetahs in the Phinda Resource Reserve, Kwazulu-Natal, South Africa. $\mathrm{PhD}$ thesis, University of Pretoria.

KaLIKAWA, M.C. 1990. Baseline vegetation description at artificial watering points of Central Kalahari Game Reserve. African Journal of Ecology 28: 253-256.

Low, A.B. \& A.G. Rebelo. 1996. Vegetation of South Africa, Lesotho and Swaziland. Pretoria: Department of Environmental Affairs and Tourism.

Mills, G. \& L. Hes. 1997. The complete book of southern African mammals. Cape Town: Struik Winchester.

Mills, M.G.L. \& P.F. Retief. 1984. The effect of windmill closure on the movement patterns of ungulates along the Auob riverbed. Koedoe 27: 107-118.

Mizutani, F. \& P.A. Jewell. 1998. Home-range and movements of leopards on a livestock ranch in Kenya. Journal Zoology, London 244: 269-286.

Owen-Smith, N. 1996. Ecological guidelines for waterpoints in extensive protected areas. South African Journal of Wildlife Research 26: 107112.

PACKER, C. 1996. Who rules the park? Wildife Conservation May/June: 36-39.

Packer, C., L. Herbst, A.E. Pusey, J.D. Bygott, J.P. Hanby, S.J. Cairns \& M.B. Mulder. 1988. Reproductive success of lions. In: CLuTTONBrock, T.H. (ed.). Reproductive Success. Chicago: University of Chigago Press.

PACKer, C. \& A.E. Pusey. 1995. The lack clutch in a communal breeder: Lion litter size is a mixed evolutionary stable strategy. The American Naturalist 145: 833-841.

Peel, M.J.S. \& G.P. Montagu. 1999. Modelling predator-prey interactions on a Northern Province Game Ranch. South African Journal of Wildlife Research 29: 31-34.

RudnaI, J. 1973. Reproductive biology of lions (Panthera leo massaica Neumann) in Nairobi National Park. East African Wildlife Journal 11: 241-253.

Schaller, G.B. 1972. The Serengeti Lion. Chicago: University of Chigago Press.

SEAman, D.R. \& R.A. Powell. 1996. An evaluation of the accuracy of kernel density estimators for home range analysis. Ecology 77: 2075-2085.

SMuTs, G.L. 1976. Population characteristics and recent history of lions in two parts of the Kruger National Park. Koedoe 19: 153-164.

StANDER, P.E. 1991. Demography of lions in the Etosha National Park, Namibia. Madoqua 18: 1-9. 
VAN ORSDOL, K.G. 1984. Foraging behaviour and hunting success of lions in Queen Elizabeth National Park, Uganda. African Journal of Ecology 22: 79-99.

VAN ORSDOL, K.G., J.P. HANBY \& J.D.BYGOTT. 1985. Ecological correlates of lion social organisation. Journal of Zoology, London 206: 97-112.

VARTAN, S. 2002. Overpopulation and inbreeding in small game reserves: the lion Panthera leo as a case study. MSc thesis, University of Cape Town, Rondebosch.

VILJOEN, P.C. 1993. The effects of changes in prey availability on lion predation in a large natural ecosystem in northern Botswana. Symposium Zoological Society, London 65: 193-213.

Western, D. 1975. Water availability and its influence on the structure and dynamics of a savannah large mammal community. East African Wildlife Journal 13: 265-286. 